\title{
A produção acadêmica publicada na revista Gestão \& Produção de 1999 a 2010: tendências e direções para pesquisas futuras
}

\author{
Academic research published in the Management \& \\ Production Journal (G\&P, 1999-2010): trends and future \\ research directions
}

\author{
Lucas Nogueira Bortollossi ${ }^{1}$ \\ Mauro Sampaio ${ }^{2}$
}

\begin{abstract}
Resumo: Esta pesquisa analisou as publicações da revista Gestão \& Produção (G\&P) nos últimos doze anos. O objetivo foi identificar as tendências de pesquisa na área "Gestão da Produção e Operações" (POM): sua diversidade em termos de quantidade, tópico de interesse, fonte de dados, contribuição da pesquisa e redes sociais. Os artigos da revista G\&P foram classificados quanto ao tipo de contribuição primária (conceitual, aplicação da teoria e construção de teoria), abordagem de coleta de dados (questionário, estudo de caso, pesquisa qualitativa, pesquisa de arquivo, pesquisa de laboratório), técnica de análise de dados (estatística básica, técnicas de análise multivariada e modelagem matemática) e tópico de interesse (estratégia de operações, qualidade, gestão da cadeia de suprimento, entre outros). Com o levantamento realizado, observa-se que a pesquisa em gestão de operações cresceu consideravelmente na última década. $\mathrm{O}$ foco dos artigos amadureceu, passou de uma ênfase de artigos descritivos para uma vertente mais voltada à aplicação de teoria. A principal das fontes foram casos. Sugestões de direções para pesquisas futuras foram propostas.
\end{abstract}

Palavras-chave: Produção acadêmica. Metodologia. Técnicas de estatística multivariada. Produção e operação.

\begin{abstract}
This study is a review and evaluation of studies published in a Brazilian journal of management \& production $(G \& P)$ from 1999 to 2010 in order to investigate the diversity of articles in terms of the purposes of research, data collection approaches, and data analysis techniques. The research articles were classified based on their primary purpose (theory building, application, and concepts), data collection approach (case study, qualitative research, archival research, survey-based research, laboratory research, and field research), data analysis technique (descriptive statistics, various multivariate statistical techniques, and mathematical modeling), and operations topics (strategy, quality, and supply chain management). The numbers of articles published increased substantially between 1999 to 2010. The focus of the articles on the manufacturing industry published in this journal changed considerably, and more recently the gap between the number of manufacturing and service-focused articles on production and operations management (POM) has reduced. While previous articles published in the G\&P journal were based on conceptual descriptions, our results indicate that the journal has published articles based on theory and application. Case study is the most widely used method for data collection. Directions for future research in operations management were also discussed.
\end{abstract}

Keywords: Academic research. Methodology. Multivariate statistical techniques. Production and operation.

\section{Introdução}

Nas últimas décadas, a mudança no cenário competitivo para um mercado mais globalizado promoveu e incentivou o ensino e a pesquisa no campo de Gestão de Produção e Operação (ARKADER, 2003). Até o presente momento, os problemas de Produção e Operações foram estudados segundo três perspectivas: a busca de melhorias isoladas em áreas de decisões de operações, a busca do alinhamento entre áreas de decisões de operações e a estratégia do negócio e, finalmente, a busca de melhorias na gestão da cadeia de suprimentos. Independente da perspectiva adotada, a maioria dos estudos sugere que a gestão de produção

\footnotetext{
${ }^{1}$ Centro Universitário da FEI, Av. Humberto de Alencar Castelo Branco, 3972, CEP 09850-901, São Bernardo do Campo, SP, Brasil, e-mail: lucas.bortollossi@gmail.com

2 Programa de Mestrado em Engenharia Mecânica, Centro Universitário da FEI, Av. Humberto de Alencar Castelo Branco, 3972 , CEP 09850-901, São Bernardo do Campo, SP, Brasil, e-mail: msampaio@fei.edu.br
}

Recebido em 15/9/2010 — Aceito em 26/9/2011

Suporte financeiro: PBIC do Centro Universitário da FEI. 
e operações é um importante componente na estratégia de toda e qualquer organização (HAYES et al., 2004), sendo cada vez mais reconhecida como aspecto competitivo relevante.

Enquanto a literatura em Gestão de Produção e Operação (POM) é rica em ambientes de países desenvolvidos com ocasionais crises de identidade (SPRAGUE, 2007), ela é carente em identificar características, modelos de gestão e peculiaridades das operações em países emergentes, como Brasil, Rússia, China e Índia, conhecidos na literatura como economias BRICs (GOLDMAN..., 2007). Especula-se que esses países podem se tornar a maior força na economia mundial em um futuro próximo, sendo, portanto, estratégicos para empresas globais. O crescimento das vendas no mercado automotivo, por exemplo, é da ordem de $20 \%$ ao ano em países emergentes, enquanto em mercados maduros, como EUA, Europa Ocidental e Japão, as taxas de crescimento são nulas ou negativas. Dentro dos BRICs, haveria uma clara divisão de funções: o Brasil e a Rússia ficariam responsáveis pela produção de alimentos, matéria-prima e petróleo. Já os negócios de manufatura seriam realizados na Índia e na China, devido à maior concentração de mão de obra e tecnologia. Ocorreu, portanto, um crescimento na importância das operações no Brasil e em outros países emergentes no cenário mundial.

As pesquisas de POM brasileiras são publicadas em diversos periódicos nacionais. A Revista Gestão \& Produção (G\&P), criada em 1994, vem ocupando uma posição de destaque na comunidade acadêmica de Engenharia de Produção como um dos mais importantes periódicos da área. Consequentemente, esta pesquisa avaliou as publicações na revista G\&P, nos últimos doze anos, com o objetivo de investigar a evolução dos tópicos de interesse em POM. Enquanto estudos anteriores focaram temas específicos, como produção enxuta (GODINHO FILHO; FERNANDES, 2004) e gestão da cadeia de suprimento (TEIXEIRA; LACERDA, 2010), este trabalho tem um escopo mais amplo e avalia de forma sistemática os artigos publicados entre 1999 e 2010. Dessa forma, reúne informações sobre o estado da arte de pesquisa em POM e fornece direções futuras para pesquisas nesta área.

Em resumo, a pesquisa pretende responder às seguintes questões: Quais os principais temas de interesse em POM publicados na revista G\&P nos últimos doze anos? Quais as metodologias de pesquisa mais utilizadas? Quais os pesquisadores e instituições que mais publicaram na revista Gestão \& Produção? Quem são os pesquisadores e instituições que possuem maior número de coautorias, no período estudado?

$\mathrm{O}$ trabalho está organizado da seguinte maneira. A primeira seção faz uma revisão da literatura sobre a produção acadêmica em POM no País. Em seguida, é apresentada a descrição da metodologia usada. A terceira seção apresenta os resultados encontrados. Finalmente, as considerações finais, as limitações do estudo e as diretrizes para pesquisas futuras são apresentadas na quarta seção.

\section{Revisão da literatura}

A pesquisa acadêmica em $\mathrm{POM}$ foi investigada por diversos autores em países desenvolvidos (BUFFA, 1980; CHASE, 1980; MILLER; GRAHAM, 1981; MEREDITH et al., 1989; GUPTA; VERMA; VICTORINO, 2006) (entre outros) e alguns pesquisadores brasileiros (ARKADER, 2003), empregando diferentes metodologias e escopos de interesse.

Vários autores (BUFFA, 1980; CHASE, 1980; MEREDITH et al., 1989) criticaram a área de POM, nos anos 80 e 90, por produzir artigos demasiadamente teóricos, baseados em modelagem e simulação, o que culminava em pouca utilidade prática. De fato, a associação da engenharia de produção com a ciência de decisão foi significativa e contribuiu para alienar ainda mais a área POM, afastando-a das demais áreas gerenciais, como o marketing, as finanças e a estratégia (ARKADER, 2003). Entretanto, Gupta, Verma e Victorino (2006) revelam que a área POM respondeu à altura as críticas recebidas e publicou mais artigos empíricos no período de 1992 a 2005.

No Brasil, Arkader (2003) avaliou a publicação em POM, na área de administração, e verificou que os temas pesquisados estavam em consonância com temas publicados no contexto internacional. Tal fato pode significar atualidade ou apenas reprodução de pesquisas americanas e europeias no contexto nacional. Arkader (2003) também notou que os pesquisadores de engenharia eram mais produtivos do que as escolas de administração que até evitam tratar operações como tema de estudo e ensino.

Slack, Lewis e Bates (2004) apontaram outros aspectos problemáticos da produção acadêmica em POM: a ênfase excessiva em manufatura e pouca atenção às pesquisas em serviços, além de divergências entre as prioridades de temas dos executivos do mercado e a agenda dos pesquisadores de operações. Esses aspectos podem ser interpretados como: a área POM faz pesquisas empíricas, mas ainda de temas não relevantes para a prática.

$\mathrm{Na}$ literatura de engenharia de produção, encontram-se poucos trabalhos investigando a produção acadêmica, apenas alguns artigos focaram temas específicos, como Teixeira e Lacerda (2010), que trataram da produção acadêmica em Gestão da Cadeia de Suprimentos, e Godinho Filho e Fernandes (2004), que focalizaram a manufatura enxuta. Embora sejam interessantes e válidos, esses estudos revelam pouco sobre a tendência da área. 
Enfim, nesta seção mostrou-se um resgate da literatura e produção acadêmica em POM. Com isso foi possível perceber que, embora alguns autores tenham refletido sobre a produção no campo, poucos estudos foram realizados na área de engenharia de produção, considerando um escopo mais amplo, tal qual a proposta deste artigo.

\section{Metodologia}

A seção de metodologia apresenta as seguintes partes: 1) seleção da revista acadêmica; 2) seleção dos artigos; e 3) critérios para classificação dos artigos.

\subsection{Seleção da revista acadêmica}

A pesquisa se restringe à revista G\&P, que publica trabalhos originais que têm resultados de estudos e pesquisas na área de Engenharia de Produção. A G\&P é considerada uma das principais publicações acadêmicas da área e o trabalho focou somente essa revista pela natural dificuldade de se investigar toda a área de POM em um único estudo. A Tabela 1 mostra a classificação das principais revistas da Engenharia de Produção.

\subsection{Seleção dos artigos}

Foram analisados 341 artigos da revista G\&P durante o período de 1999 a 2010. Esse quantitativo é uma amostra suficiente para investigar as tendências de pesquisa em POM em uma revista (GUPTA; VERMA; VICTORINO, 2006).

\subsection{Tipo de classificação}

Este artigo utilizou um sistema de classificação de artigos desenvolvido e aplicado por Gupta, Verma e Victorino (2006), para avaliar a produção da revista Production Operations Management. Os artigos foram catalogados em sete dimensões: foco, tópico de interesse, fonte de dados, tipo de contribuição, técnica de análise, período e autores. Ao menos dois membros da equipe realizaram as classificações dos artigos. Embora não se tenha calculado formalmente os índices de concordância entre avaliadores (BOYER; VERMA, 2000), houve um elevado grau de consenso entre os membros da equipe. Portanto, o impacto da avaliação subjetiva de um artigo individual pode ser considerado mínimo sobre o resultado global da pesquisa.

Tendo em conta que a temática POM assume formas diferentes, dependendo do tema abrangido e da natureza da pergunta de pesquisa, vários artigos reuniram mais de uma tipologia dentro de cada dimensão listada. Por exemplo, é possível que um artigo seja baseado em mais de uma abordagem de coleta de dados e/ou pode ter utilizado mais de uma técnica de análise.

\subsubsection{Foco do artigo}

Cada artigo foi classificado de acordo com o seu foco de interesse: manufatura ou serviços. Em alguns casos, os artigos foram classificados nas duas categorias simultaneamente, devido à amplitude de escopo.

\subsubsection{Tópicos de interesse}

Essa dimensão tem o objetivo de investigar e identificar os principais temas pesquisados em POM. Foi utilizada uma lista de tópicos de interesse da área de engenharia de produção determinados pela Associação Brasileira de Engenharia de Produção (ABEPRO), conforme mostra a Tabela 2. Uma publicação pode

Tabela 1. Lista de publicações em POM do Qualis.

\begin{tabular}{lc}
\hline \multicolumn{1}{c}{ Título } & Extrato \\
\hline Gestão \& Produção (UFSCAR) & B2 \\
Produção (São Paulo) & B2 \\
Pesquisa Operacional & B2 \\
Brazilian Journal of Operations and & B3 \\
Production Management & \\
Investigação Operacional & B3 \\
Revista Produção Online & B3 \\
Product (IGDP) & B4 \\
Produto \& Produção (Impresso) & B4 \\
Pesquisa \& Desenvolvimento & B5 \\
Engenharia de Produção & \\
Relatórios de Pesquisa em Engenharia & B5 \\
de Produção (UFF) & \\
Revista Gestão Industrial & B5 \\
\hline
\end{tabular}

Fonte: www.qualis.capes.gov.br

Tabela 2. Tópicos de Pesquisa.

\begin{tabular}{lc}
\hline \multicolumn{1}{c}{ Tópicos de pesquisa } & Código \\
\hline $\begin{array}{l}\text { Engenharia de operações e processos } \\
\text { da produção }\end{array}$ & EOPP \\
Logística & LO \\
Pesquisa operacional & PO \\
Engenharia da qualidade & EQ \\
Engenharia do produto & EP \\
Engenharia organizacional & EO \\
Engenharia econômica & EE \\
Engenharia do trabalho & ET \\
Engenharia da sustentabilidade & ES \\
Educação em engenharia da produção & EEP \\
\hline
\end{tabular}

Fonte: Associação brasileira de Engenharia de Produção (ABEPRO). 
referenciar dois ou mais tópicos, por exemplo, um artigo pode referir-se à pesquisa operacional e à logística simultaneamente.

\subsubsection{Coleta de dados}

O objetivo foi avaliar como os dados foram obtidos. O nível de disponibilidade de dados revela o grau de abertura e a facilidade da realização de pesquisas empíricas relacionadas à POM. Também revela o grau de maturidade e de rigor acadêmico das pesquisas realizadas. Quatro categorias foram utilizadas para classificar os estudos:

- Sem dados: nenhum dado foi coletado na pesquisa;

- Questionário: um questionário foi utilizado como instrumento de coleta de dados;

- Estudo de caso: as informações foram obtidas por meio de entrevistas em uma ou mais organizações;

- Dados secundários: a pesquisa utilizou fonte de dados secundários, tais como relatórios de entidades governamentais e relatórios de setores industriais.

\subsubsection{Tipo de contribuição}

A dimensão - contribuição da pesquisa - avalia o grau de contribuição para o desenvolvimento da área de POM (GUPTA; VERMA; VICTORINO, 2006). Três dimensões foram definidas para avaliar o grau de contribuição:

- Conceitual: o artigo não inclui quaisquer dados e baseia-se na lógica e discussão de enquadramentos teóricos. Nessa categoria, algumas pesquisas discutem e descrevem as práticas de POM em empresas brasileiras, fazem a introdução de problemas típicos a POM e explicam as condições passadas e atuais de operações em organizações brasileiras. Alguns estudos de POM são direcionados para ajudar na compreensão de aspectos da cultura brasileira e da dinâmica da competitividade em um mercado como o brasileiro. Naturalmente trazem pouca contribuição para a evolução da área de conhecimento POM.

- Aplicação da Teoria: nessa categoria, encontram-se os artigos que procuram aplicar a teoria de POM em empresas brasileiras. A utilização de práticas consagradas em POM é umas das preocupações constantes das organizações locais na busca de uma vantagem competitiva em produção (HAYES et al., 2004).
- Construção de Teoria: Nessa categoria estão artigos que retratam práticas de $\mathrm{POM}$ ou modelos de negócio desenvolvidos por executivos e/ou pesquisadores brasileiros. Trata-se de uma real contribuição local para o desenvolvimento da área de POM.

\subsubsection{Técnicas de análise}

A diversidade de foco de investigação e de abordagens de coleta de dados exige uma ampla gama de técnicas de análise de dados. Esta pesquisa identifica as categorias de técnicas de análises comumente utilizadas em estudos de operações, tais como:

- Métodos básicos de análise de dados: estatística descritiva, hipótese, teste de diferença entre médias (teste T, Anova, anova bivariada, manova), correlação e regressão simples.

- Técnicas multivariadas: Modelagem de equações estruturais, correlação canônica, análise multivariada de variância, regressão múltipla, regressão logística, análise conjunta, análise discriminante múltipla, modelos lineares de probabilidade, análise fatorial, análise de agrupamento, escalonamento multidimensional, análise de correspondência.

- Modelos Matemáticos: modelos prescritivos (programação linear, Redes, programação inteira, programação de meta, LEC, programação não linear), modelo preditivos (análise de regressão, séries temporais) e modelos descritivos (simulação, filas, PERT, modelos de estoque)

- Pesquisa Qualitativa: estudo de caso único e estudo de casos múltiplos e pesquisa ação.

\subsubsection{Período}

Esta dimensão é o registro da época da publicação.

\subsubsection{Análise de redes sociais}

Uma rede social é um conjunto de pessoas em que cada indivíduo está familiarizado com o trabalho de outros indivíduos da comunidade. Essa rede pode ser apresentada por um conjunto de vértices representando pessoas, unidas em pares por linhas que demonstram a interação e troca de conhecimento. Pode-se, a princípio, construir a rede social de uma empresa, de uma universidade, ou de qualquer outra comunidade, até inclusive a rede social de todo o mundo. As redes sociais têm sido objeto de interesse de estudos teóricos e empíricos na área de ciências sociais há pelo menos 50 anos, em parte devido ao interesse inerente pelos padrões de interação humana, mas também porque sua estrutura tem implicações importantes sobre o processo de difusão do conhecimento. 
Neste artigo, o interesse específico foi o estudo da estrutura das redes sociais de professores pesquisadores em operações. Dois pesquisadores foram considerados conectados se tiveram ao menos um artigo em coautoria. Segundo Newman (2001), essa é uma definição razoável de compartilhamento de conhecimento científico: a maioria das pessoas que tem artigo em conjunto, provavelmente se conhece muito bem, embora existam casos de pesquisadores que se conheçam bem, mas nunca chegaram a elaborar a redação de um mesmo artigo.

A ideia de estudar padrões de colaboração, usando os dados extraídos dos registros da publicação não é nova. Há um substancial corpo de literatura em ciência da informação que lida com padrões de coautoria (NEWMAN, 2001) e os padrões de cocitação (CHARVET; COOPER, 2008) (isto é, as conexões entre autores por meio da citação de suas obras na literatura acadêmica).

\section{Resultados}

Esta seção apresenta os resultados da investigação e está dividida em oito subseções: manufatura vs. serviços, quantitativo vs. qualitativo, tópicos de interesse, coleta de dados, tipo de contribuição, técnica de análise, analise cruzada de dados e análise de redes sociais

\subsection{Manufatura vs. serviços}

A Tabela 3 apresenta a distribuição de artigos publicados na G\&P entre 1999 e 2010 classificados quanto ao foco em manufatura ou serviços. Conforme mencionado na seção de metodologia, em alguns casos o artigo foi classificado nas categorias manufatura e serviços simultaneamente, devido à amplitude de seu escopo.

A Figura 1 mostra que a distância entre o foco dos artigos em manufatura e serviços diminuiu nos últimos anos. Esse resultado é uma tendência positiva que aponta para o desenvolvimento de pesquisa de operações em serviços.

Enquanto o IBGE (INSTITUTO..., 2008) observou que o setor de serviços representa $66 \%$ do PIB no Brasil, tradicionalmente tem-se encontrado na literatura de POM o foco no setor industrial (SLACK; LEWIS; BATES, 2004). Embora, entre 1999-2010, cerca de $70 \%$ dos artigos publicados na revista G\&P ainda tenham sido em manufatura, a diferença entre o número de artigos publicados em manufatura e em serviço diminuiu. Observa-se, assim, que a G\&P vem optando por uma gradual transição para a publicação de artigos em serviços.

\subsection{Quantitativo vs. qualitativo}

A Tabela 4 apresenta a distribuição de artigos publicados na G\&P durante 1999-2010, segundo a orientação do método de pesquisa: qualitativa e quantitativa.

A Figura 2 mostra uma inversão da orientação macro do método de pesquisa. Até 2008, predominavam

Tabela 3. Tipo de artigo publicado com foco em manufatura vs. serviços.

\begin{tabular}{ccc}
\hline $\begin{array}{c}\text { Ano de } \\
\text { publicação }\end{array}$ & $\begin{array}{c}\text { Foco em } \\
\text { manufatura }\end{array}$ & $\begin{array}{c}\text { Foco em } \\
\text { serviços }\end{array}$ \\
\hline 1999 & 18 & 3 \\
2000 & 21 & 2 \\
2001 & 13 & 7 \\
2002 & 18 & 6 \\
2003 & 13 & 9 \\
2004 & 24 & 12 \\
2005 & 28 & 7 \\
2006 & 24 & 19 \\
2007 & 34 & 9 \\
2008 & 31 & 15 \\
2009 & 34 & 21 \\
2010 & 13 & 2 \\
\hline
\end{tabular}

Fonte: os autores.

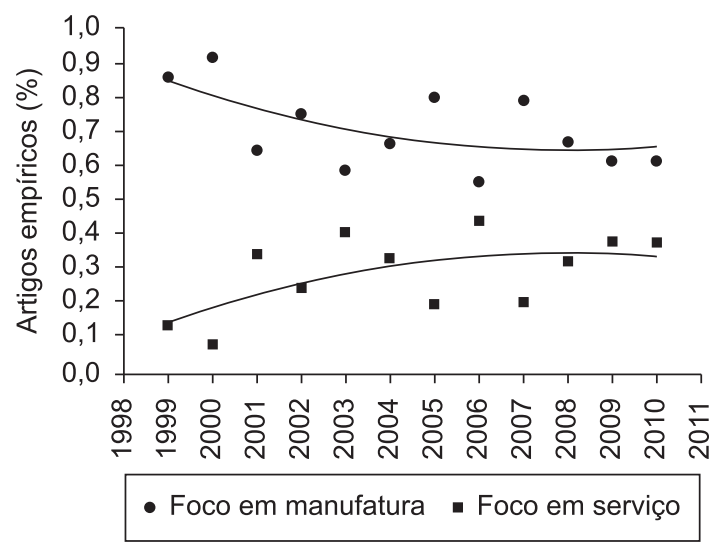

Figura 1. Percentual de artigos com foco em manufatura e serviços publicados na G\&P. Fonte: os autores.

Tabela 4. Tipo de artigo publicado com foco em pesquisa Qualitativa vs. Quantitativa.

\begin{tabular}{ccc}
\hline $\begin{array}{c}\text { Ano de } \\
\text { publicação }\end{array}$ & Qualitativo & Quantitativo \\
\hline 1999 & 14 & 7 \\
2000 & 13 & 10 \\
2001 & 16 & 4 \\
2002 & 8 & 16 \\
2003 & 15 & 7 \\
2004 & 15 & 21 \\
2005 & 21 & 14 \\
2006 & 24 & 19 \\
2007 & 24 & 19 \\
2008 & 24 & 22 \\
2009 & 24 & 31 \\
2010 & 10 & 5 \\
\hline
\end{tabular}

Fonte: Os autores. 
métodos qualitativos; desde então aumentou a proporção de métodos com orientação mais quantitativa.

Os artigos qualitativos ainda predominam na revista G\&P (52\%), porém o número de artigos com abordagem mais quantitativa aumentou. Esse resultado é uma tendência positiva: a adoção de métodos mais quantitativos pelos pesquisadores brasileiros está mais em sintonia com a orientação de pesquisa de revistas internacionais da área de POM (GUPTA; VERMA; VICTORINO, 2006).

\subsection{Tópicos de interesse}

Os trabalhos publicados em G\&P abrangeram uma variedade de temas que foram classificados nas subáreas de conhecimento definidas pela ABEPRO. Os resultados são apresentados na Figura 3. Conforme mencionado na seção de metodologia, em alguns casos o artigo foi classificado em mais de uma área de conhecimento, devido à amplitude de seu escopo.

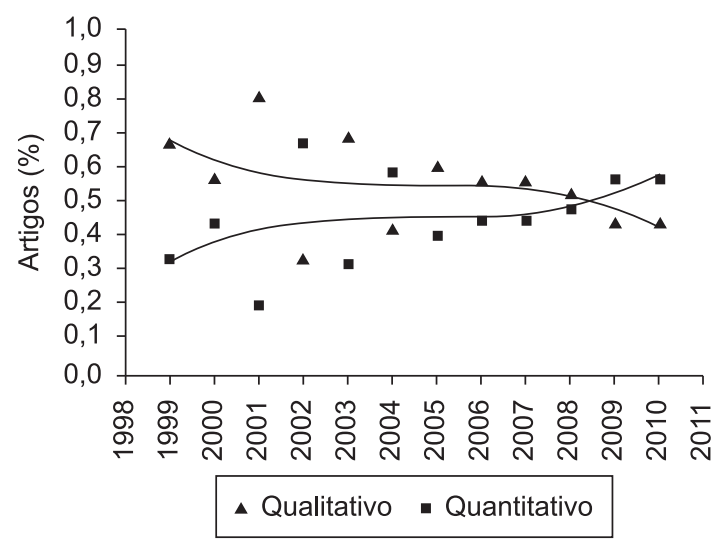

Figura 2. Percentual de artigos com foco em métodos qualitativos e quantitativos publicados na G\&P. Fonte: Os autores.
A Figura 3 mostra que os temas mais populares da pesquisa são de engenharia de operações e processos da produção $(22,4 \%)$, engenharia organizacional $(20,9 \%)$ e pesquisa operacional $(20,0 \%)$. O segundo grupo de temas mais populares (entre 5 e $20 \%$ ) inclui logística $(14,5 \%)$ e engenharia da qualidade $(7,2 \%)$. As demais áreas de conhecimento $(<5 \%)$ são os temas menos populares.

A Figura 4 mostra a frequência de cobertura de área de conhecimento por períodos: I (1999-2002), II (2002-2007) e III (2007-2010).

Conforme mostrado na Figura 4, a pesquisa acadêmica sofreu uma mudança de comportamento a partir do período II. Logística (LO), engenharia da sustentabilidade, engenharia econômica (EE) e engenharia do produto (EP) são agora áreas de conhecimento mais populares. Há potencial para a investigação na interface entre as operações e outras áreas, como contabilidade, finanças, gestão de recursos humanos, sistemas de informação e marketing (BUHMAN; KEKRE; SINGHAL, 2005). É evidente que, com a rápida proliferação da tecnologia da informação, a expansão da tecnologia do setor dos serviços e o crescimento das redes de suprimentos globais, há necessidade de investigações sobre novos problemas de operações.

\subsection{Coleta de dados}

A Figura 5 mostra a classificação dos artigos segundo a abordagem de coleta de dados utilizada. Cerca de metade dos artigos publicados utilizou-se de casos $(52 \%)$, seguida pela pesquisa sem dados $(21 \%)$ e pela pesquisa a partir de dados secundários (19\%); a investigação por questionário tem sido utilizada muito raramente (cerca de $8 \%$ ).

A Figura 5 também mostra o padrão de fontes de coleta de dados nos três períodos de tempo do estudo. No período I, as maiores porcentagens de artigos são

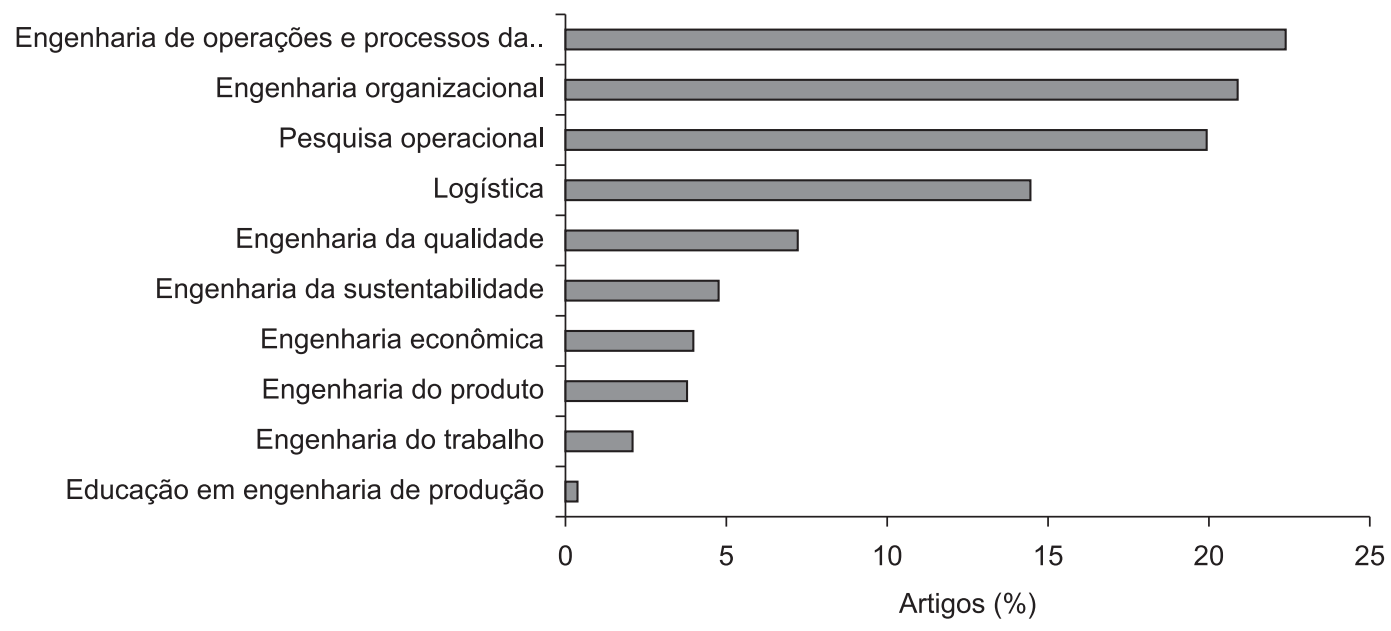

Figura 3. Percentual de artigos na revista G\&P por área de conhecimento. Fonte: Os autores. 
sem dados ou baseados em casos. Nos períodos II e III, reduziram-se as publicações de artigos sem dados e houve um aumento das publicações de artigos baseados em dados secundários, como relatórios governamentais ou da indústria.

A coleta de dados para pesquisa em POM no Brasil não é uma tarefa fácil. A cultura tradicional de segredo industrial torna difícil obter informações privilegiadas das empresas de propriedade privada. A pesquisa baseada em casos foi a abordagem mais utilizada, seguida pelo uso de dados secundários, enquanto questionários foram utilizados em casos raros. Portanto, acredita-se que existe potencial para pesquisas por meio de questionários e dados de laboratório em gestão de operações. Outras disciplinas, como organizações, marketing, medicina e as ciências físicas utilizam-se dessa abordagem para coleta de dados.

Nota-se também que apenas um pequeno número de trabalhos foi baseado em múltiplas abordagens para coleta de dados, apontando para uma falta de triangulação. Com o amadurecimento da pesquisa de POM, é desejável a publicação de mais artigos

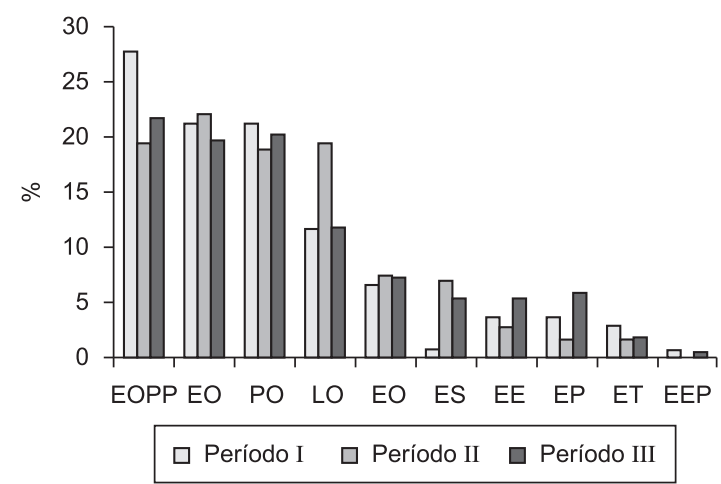

Figura 4. Evolução do percentual de assuntos de interesse da revista G\&P. Fonte: Os autores. baseados em múltiplos métodos de coleta de dados. Além disso, a combinada utilização de técnicas de investigação deveria ser incentivada, porque tem o potencial de oferecer uma análise mais profunda das questões estudadas.

\subsection{Tipo de contribuição}

Cada artigo da pesquisa traz uma contribuição para a literatura de POM. O rastreamento das contribuições fornece insights sobre o grau de maturidade da pesquisa em POM no Brasil. A Figura 6 mostra a evolução das contribuições da investigação durante os três períodos em estudo: conceitual, aplicação da teoria e construção teórica.

Conforme mostrado na Figura 6, o tipo de contribuição mais comum em todos os períodos foi conceitual, artigos voltados à descrição, introdução, ou revisão da literatura de problemas de POM. Esses artigos são típicos de áreas de conhecimento em estágio rudimentar, quando os pesquisadores estão mais preocupados em divulgar conceitos preexistentes do que desenvolver novos conceitos. A sua contribuição é menor em relação a outros tipos. No entanto, o percentual de artigos conceituais diminuiu com o tempo: de $60,2 \%$ no período I, a $56 \%$ no período II, e $54,7 \%$ no período III. Em contraste com a tendência de artigos conceituais, a percentagem de artigos de aplicação de teoria aumentou ao longo do tempo. $\mathrm{O}$ percentual subiu de $36,4 \%$ no período I para $44,7 \%$ no período III.

A construção de teoria teve a incidência muito baixa, evento raro nas pesquisas em POM no Brasil. A ampliação da publicação desse tipo de artigo traz uma contribuição para o desenvolvimento da área de POM, pois eles não se restringem a descrever um conceito ou a aplicar uma prática consagrada no ambiente de negócio brasileiro, mas desenvolvem

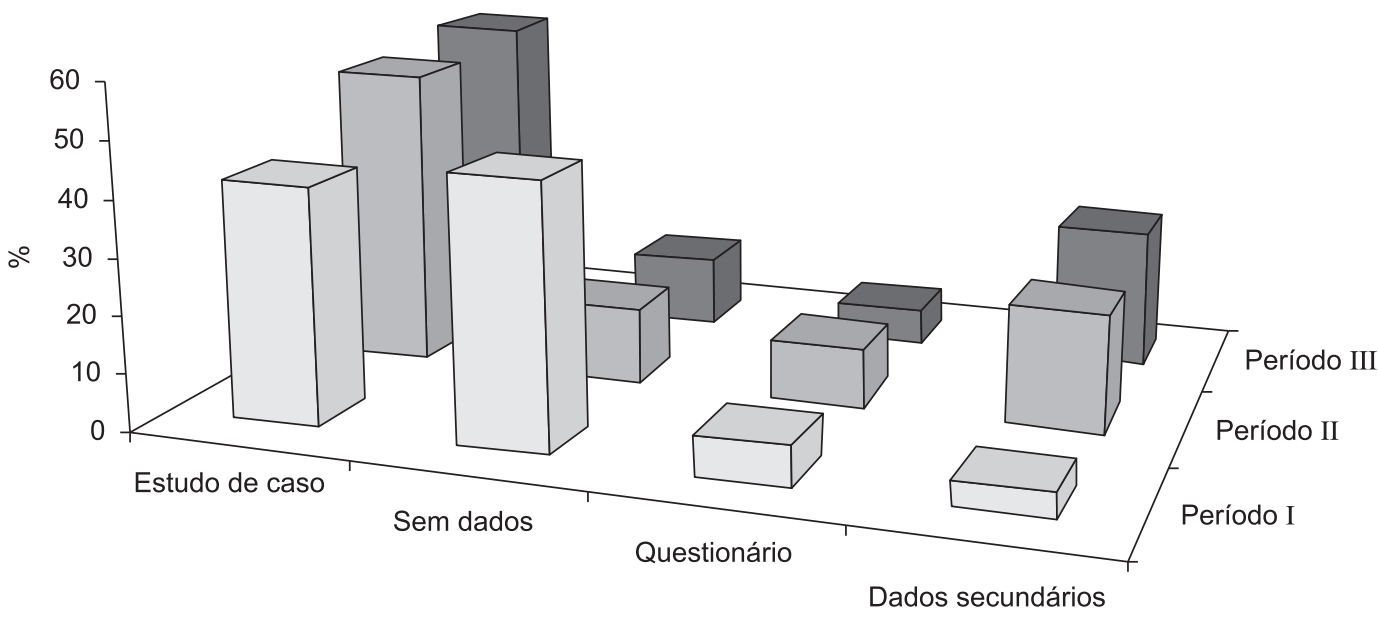

Figura 5. Tipo de fonte de dados dos artigos publicados na revista G\&P. Fonte: Os autores. 
modelos e conceitos elaborados por executivos e/ou pesquisadores brasileiros.

Esse resultado reforça a oportunidade de publicação de artigos mais voltados à construção de teoria, fato que contribuiria para a maturidade da pesquisa em POM no Brasil.

\subsection{Técnicas de análise}

Foram identificadas variadas técnicas de análise dos dados nos artigos. Como mostra a Figura 7, a gama de técnicas varia desde técnicas qualitativas, passando por modelos matemáticos até técnicas multivariadas.

A técnica de análise utilizada é influenciada pelo tipo de contribuição da pesquisa e de abordagem de coleta de dados. A predominância de pesquisas qualitativas na G\&P levou a uma maior incidência do uso de técnicas qualitativas. Mas muitos artigos fizeram somente uma revisão da literatura. Assim, a área de operações carece do uso de técnicas multivariadas de análise de dados, para chegar a resultados mais robustos.

\subsection{Análise cruzada de dados}

Para explorar a inter-relação entre diferentes facetas da pesquisa, foram realizadas análises cruzadas dos dados, conforme mostram as Tabelas 5 a 7 . As Tabelas 5 e 6 apresentam a relação entre o tipo de contribuição do artigo e a abordagem de coleta de dados. Em ambas as Tabelas 5 e 6 as percentagens das linhas somam $100 \%$. A Tabela 5 mostra que o tipo de estudo (conceitual, aplicação ou construção de teoria) tem relação com a escolha do método. Por exemplo, estudos quantitativos são utilizados principalmente em aplicações de teoria $(69,7 \%)$, enquanto a pesquisa qualitativa é usada principalmente em artigos conceituais (80,3\%).

As percentagens de linhas na Tabela 6 mostram a relação entre os tipos de contribuição e a abordagem de coleta de dados. As principais abordagens utilizadas

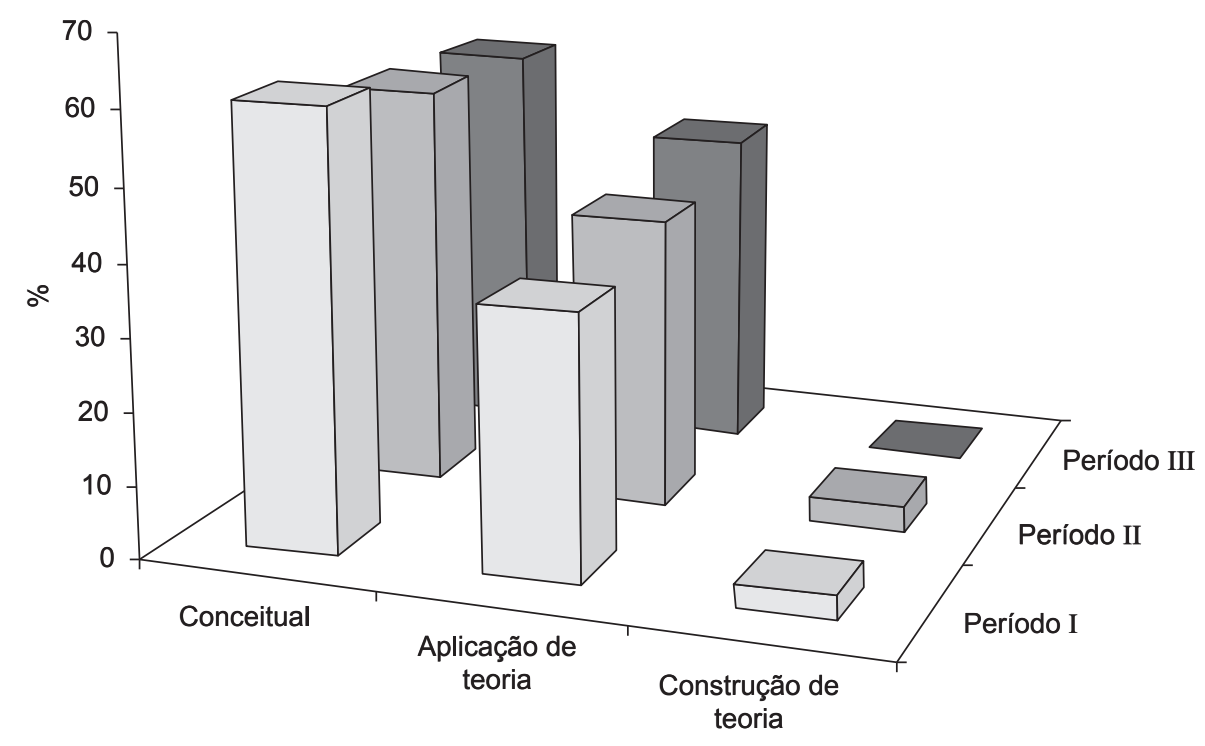

Figura 6. Tipo de contribuição dos artigos publicados na revista G\&P. Fonte: Os autores.

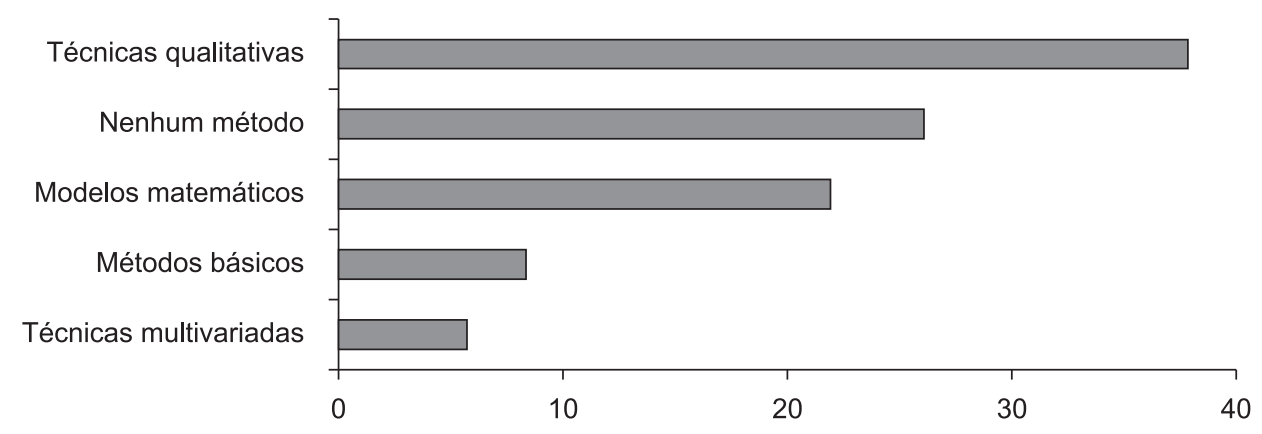

(\%)

Figura 7. Abordagem de técnica de análise utilizada. Fonte: Os autores. 
Tabela 5. Percentagem em colunas.

\begin{tabular}{lcc}
\hline & $\begin{array}{c}\text { Qualitativo } \\
(\boldsymbol{\%})\end{array}$ & $\begin{array}{c}\text { Quantitativo } \\
(\mathbf{\%})\end{array}$ \\
\hline Conceitual & 80,3 & 28,0 \\
Aplicação de teoria & 17,3 & 69,7 \\
Construção de teoria & 2,4 & 2,3 \\
Total & 100,0 & 100,0 \\
\hline
\end{tabular}

Fonte: os autores.

Tabela 6. Percentagem em linhas.

\begin{tabular}{lccc}
\hline & $\begin{array}{c}\text { Qualitativo } \\
(\boldsymbol{\%})\end{array}$ & $\begin{array}{c}\text { Quantitativo } \\
(\mathbf{\%})\end{array}$ & $\begin{array}{c}\text { Total } \\
(\boldsymbol{\%})\end{array}$ \\
\hline Conceitual & 77,3 & 22,7 & 100,0 \\
$\begin{array}{l}\text { Aplicação de } \\
\text { teoria }\end{array}$ & 22,8 & 77,2 & 100,0 \\
$\begin{array}{l}\text { Construção de } \\
\text { teoria }\end{array}$ & 55,6 & 44,4 & 100,0 \\
\hline
\end{tabular}

Fonte: Os autores.

Tabela 7. Quantidade de artigos, pesquisadores e instituições por período.

\begin{tabular}{cccc}
\hline Período & Artigos & Pesquisadores & Instituições \\
\hline $1999-2002$ & 88 & 160 & 52 \\
$2003-2006$ & 136 & 255 & 87 \\
$2007-2010$ & 159 & 335 & 90 \\
\hline
\end{tabular}

Fonte: os autores.

para a construção de teoria são métodos qualitativos $(55,6 \%)$ e quantitativos $(44,4 \%)$.

\subsection{Análise de redes sociais}

Esta seção analisou a estrutura de relacionamento entre os pesquisadores e instituições na revista Gestão \& Produção. No período estudado, foram identificados 649 pesquisadores e 149 Instituições. A Figura 8 e a Tabela 7 mostram a evolução da quantidade de artigos, pesquisadores e instituições no período de interesse.

A Figura 8 e a Tabela 7 mostram que a quantidade de pesquisadores aumentou de forma expressiva nos três períodos estudados, o que não aconteceu na mesma proporção com as instituições de ensino. Portanto, as instituições estão cada vez mais produtivas.

Essas informações tabuladas permitiram a construção da rede de colaboração entre pesquisadores que publicaram na revista Gestão \& Produção: os nós da rede são os pesquisadores e dois pesquisadores são conectados se publicaram um artigo em coautoria.

Com a análise da Figura 9, verifica-se a evolução do número de autores a cada período, e também a ampliação das publicações em coautoria, no terceiro período, quando somente quatro pesquisadores publicaram sozinhos. O período de 2007-2010 foi responsável por quase metade do volume de artigos que foram publicados pela revista. A Tabela 8 mostra

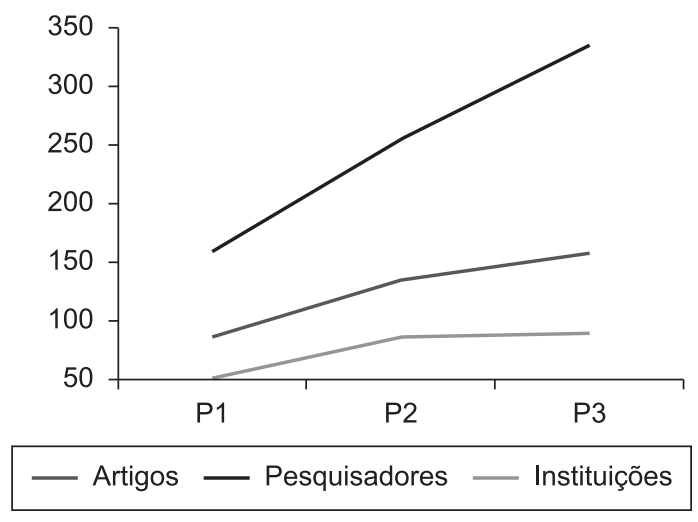

Figura 8. Evolução da quantidade de artigos, pesquisadores e instituições da G\&P. Fonte: os autores.
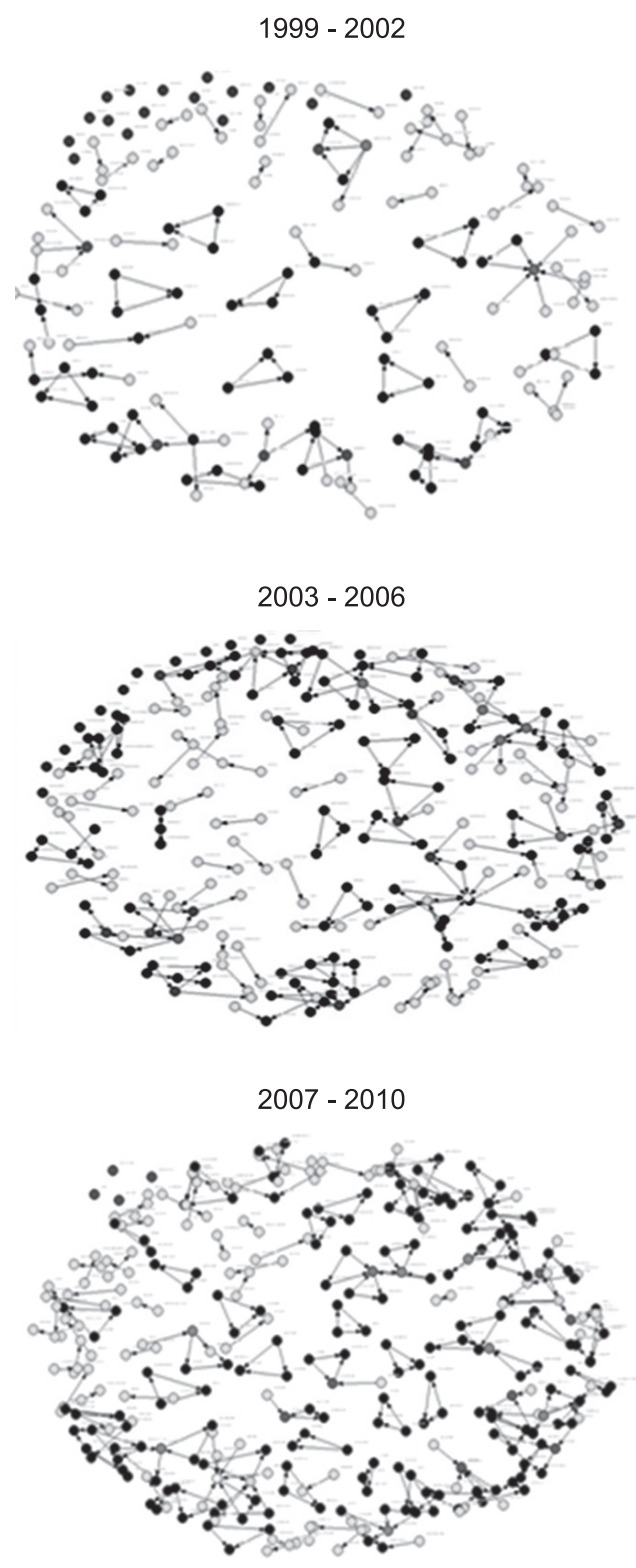

Figura 9. Evolução dos pesquisadores nos respectivos períodos. Fonte: Os autores. 
Tabela 8. Pesquisadores mais prolíferos no período estudado.

\begin{tabular}{|c|c|c|c|c|}
\hline Autores & P1 & $\mathbf{P 2}$ & P3 & Total* \\
\hline Reinaldo Morabito & 5 & 4 & 6 & 15 \\
\hline Flávio César F. Fernandes & 3 & 5 & 4 & 12 \\
\hline Miguel Afonso Sellitto & 1 & 5 & 3 & 9 \\
\hline Marly Monteiro de Carvalho & 2 & 5 & 2 & 9 \\
\hline Moacir Godinho Filho & 0 & 3 & 5 & 8 \\
\hline Alceu Gomes Alves Filho & 2 & 3 & 2 & 7 \\
\hline Flávio Sanson Fogliatto & 2 & 3 & 2 & 7 \\
\hline Fernando José Barbin Laurindo & 3 & 3 & 1 & 7 \\
\hline José Luis Duarte Ribeiro & 0 & 3 & 3 & 6 \\
\hline Sílvio R. I. Pires & 1 & 2 & 3 & 6 \\
\hline Maria Teresinha Arns Steiner & 1 & 3 & 2 & 6 \\
\hline Paulo Augusto Cauchick Miguel & 0 & 2 & 3 & 5 \\
\hline Daniel Capaldo Amaral & 2 & 0 & 3 & 5 \\
\hline Peter Wanke & 0 & 3 & 2 & 5 \\
\hline Aline Lamon Cerra & 1 & 2 & 2 & 5 \\
\hline Fernando César Almada Santos & 1 & 2 & 2 & 5 \\
\hline Luiz Fernando de Orini e Paulillo & 1 & 2 & 2 & 5 \\
\hline Jonas Lucio Maia & 0 & 2 & 2 & 4 \\
\hline Leandro dos Santos Coelho & 0 & 2 & 2 & 4 \\
\hline Adiel Teixeira de Almeida & 1 & 1 & 2 & 4 \\
\hline Luiz Antonio Nogueira Lorena & 1 & 1 & 2 & 4 \\
\hline Mario Sergio Salerno & 1 & 1 & 2 & 4 \\
\hline Luiz César Ribeiro Carpinetti & 1 & 1 & 2 & 4 \\
\hline Linda Lee Ho & 0 & 3 & 1 & 4 \\
\hline Andrea Lago da Silva & 1 & 2 & 1 & 4 \\
\hline Miguel Cezar Santoro & 3 & 1 & 0 & 4 \\
\hline
\end{tabular}

* período analisado- Jan/1999 a fev/2010 quais foram os 20 pesquisadores que mais publicaram na revista $G \& P$.

Observa-se que boa parte dos autores tem produção concentrada nos períodos 2 e 3 , o que coincide com o crescimento da área de operações em si. O autor que mais publicou foi Reinaldo Morabito, e com uma boa diferença em relação aos demais pesquisadores.

A Figura 10 apresenta a rede de colaboração entre autores, identificando quais pesquisadores têm maior centralidade na rede. Esta posição representa sua importância na rede (SCOTT, 2000; WASSERMAN; FAUST, 1994). Tal importância está relacionada àquele ator cujos laços com outros atores o tornam particularmente visível no contexto da rede.

A Figura 10 mostra os pesquisadores que tiveram maior centralidade: Reinaldo Morabito e Marly Monteiro de Carvalho. Os "nós" centrais são aqueles que tiveram maior ligação com outros pesquisadores, e os "nós" mais dispersos ao redor da circunferência são pesquisadores que apresentaram poucas coautorias e não tiveram ligação com os principais pesquisadores.

A Tabela 9 mostra os dez pesquisadores com maior grau de centralidade, ou seja, maior quantidade de interações com outros pesquisadores que publicaram na revista Gestão \& Produção no período estudado.

Cabe observar que a pesquisadora Maria Teresinha Arns Steiner está em terceiro lugar na rede de colaboração entre pesquisadores, como mostra a Tabela 9, o que não acontece na Tabela 8 (tabela de pesquisadores mais prolíferos), na qual

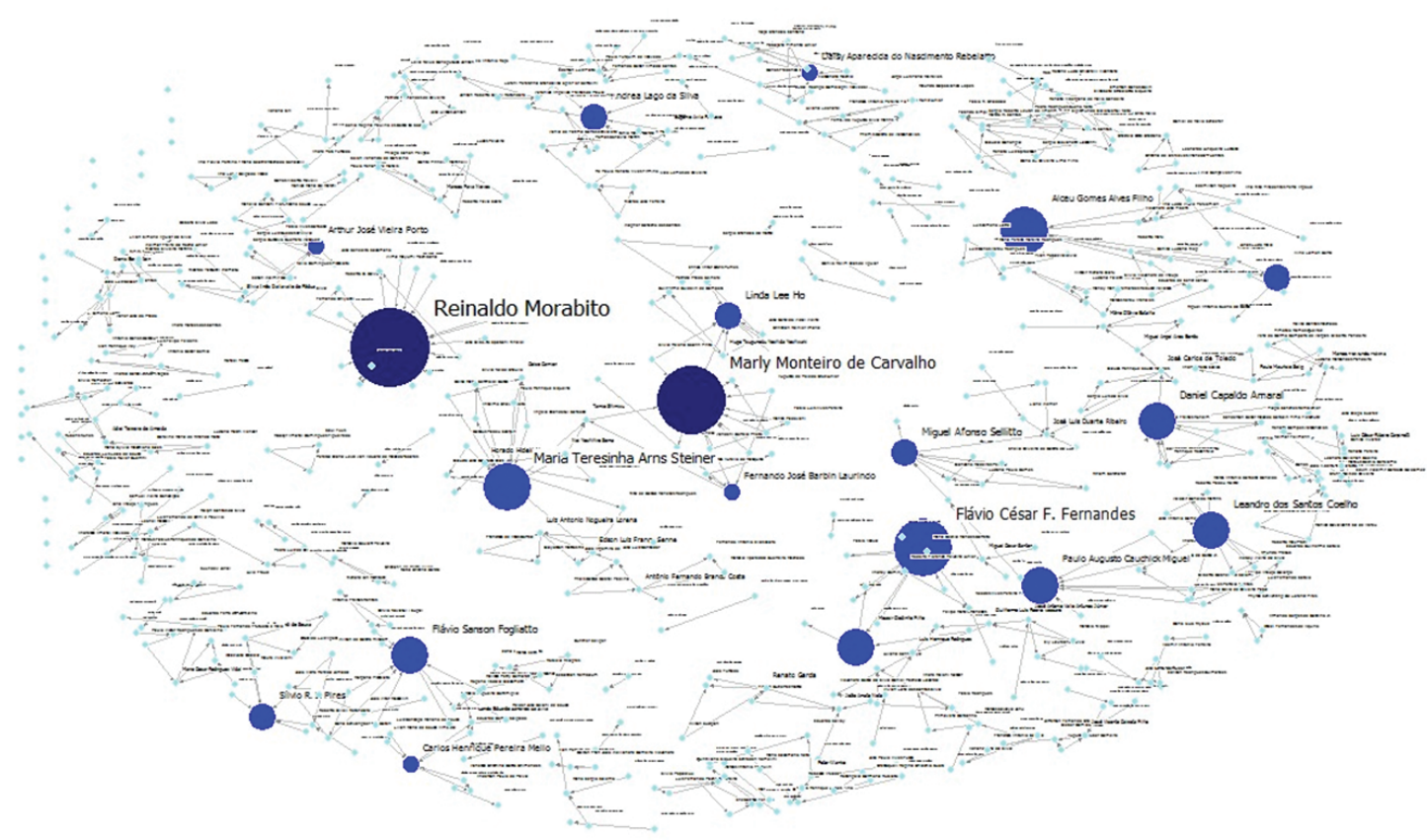

Figura 10. Rede de colaboração entre pesquisadores na Revista Gestão \& Produção. Fonte: Os autores. 
sua posição é a sétima. Isso ocorre devido a alguns pesquisadores, como Miguel Afonso Sellitto, Alceu Gomes Alves Filho, Moacir Godinho Filho e Fernando

Tabela 9. Grau de centralidade entre pesquisadores.

\begin{tabular}{clc}
\hline N & \multicolumn{1}{c}{ Autor } & $\begin{array}{c}\text { Grau de } \\
\text { Centralidade }\end{array}$ \\
\hline 1 & Reinaldo Morabito & 16 \\
2 & Marly Monteiro de Carvalho & 15 \\
3 & Flávio César F. Fernandes & 13 \\
4 & Maria Teresinha Arns Steiner & 11 \\
5 & Alceu Gomes Alves Filho & 10 \\
6 & Daniel Capaldo Amaral & 8 \\
7 & Flávio Sanson Fogliatto & 8 \\
8 & Leandro dos Santos Coelho & 8 \\
9 & Moacir Godinho Filho & 8 \\
10 & Paulo Augusto Cauchick Miguel & 8 \\
\hline
\end{tabular}

José Barbin Laurindo, publicarem com poucas coautorias. O que pode acontecer também é que em apenas uma publicação um pesquisador pode ter coautorias com dois ou três pesquisadores diferentes, elevando assim seu grau de centralidade.

Da mesma forma que com os autores, há varias instituições que publicam na revista G\&P. A Tabela 10 mostra a participação das dez instituições de ensino que mais publicaram Revista Gestão \& Produção.

As instituições listadas na Tabela 10 apresentam participação de $64 \%$ no total de publicações. A Universidade de São Paulo tem papel de destaque na revista, com $25 \%$ das publicações dos artigos, quase o dobro da segunda colocada, a Universidade Federal de São Carlos, e cinco vezes mais que a terceira colocada, a Universidade Federal de Rio Grande do Sul.

A Figura 11 mostra as universidades que tiveram maior centralidade, com isso atraem à sua volta

Tabela 10. Instituições mais produtivas.

\begin{tabular}{lrrrrc}
\hline \multicolumn{1}{c}{ Universidades mais prolíferas } & P1 & P2 & P3 & Total & $\begin{array}{c}\text { Participação no total } \\
\text { de publicaçóes (\%) }\end{array}$ \\
\hline Universidade de São Paulo - USP & 63 & 70 & 71 & 204 & 25 \\
Universidade Federal de São Carlos - UFSCar & 32 & 43 & 50 & 125 & 15 \\
Universidade Federal do Rio Grande do Sul - UFRGS & 3 & 18 & 21 & 42 & 5 \\
Universidade do Vale do Rio dos SInos - UNISINOS & 2 & 16 & 12 & 30 & 4 \\
Universidade Estadual de Campinas - UNICAMP & 12 & 8 & 8 & 28 & 3 \\
Universidade Estadual Paulista - UNESP & 2 & 7 & 17 & 26 & 3 \\
Univercidade Metodista de Piracicaba - UNIMEP & 2 & 5 & 14 & 21 & 3 \\
Universidade Federal do Rio de Janeiro - UFRJ & 3 & 5 & 12 & 20 & 2 \\
Universidade Federal de Santa Catarina - UFSC & 2 & 2 & 15 & 19 & 2 \\
Universidade Federal do Paraná - UFPR & 3 & 8 & 6 & 17 & 2 \\
\hline Total & 124 & 182 & 226 & 532 & 64 \\
\hline
\end{tabular}

Fonte: Os autores.

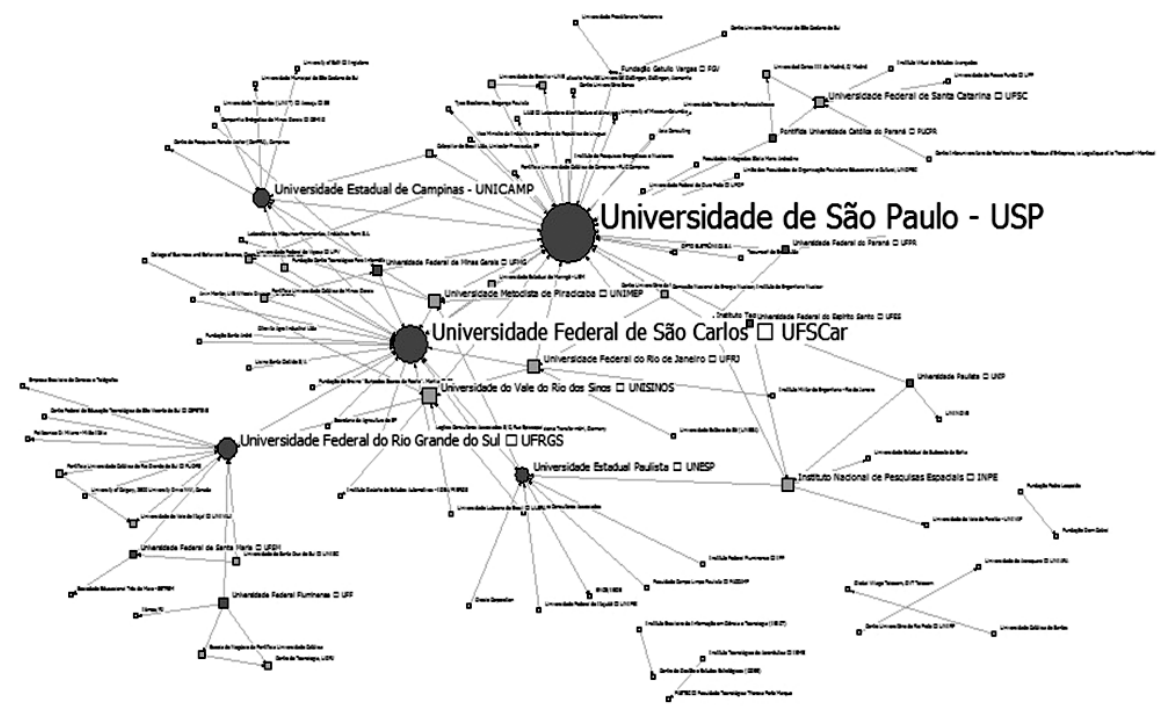

Figura 11. Rede de colaboração entre Instituições de ensino. Fonte: Os autores. 
maior quantidade de instituições de ensino de diferentes áreas de conhecimento, formando um "conglomerado", e verifica-se que alguns conglomerados estão isolados, pois não possuem ligações com alguns "nós" principais.

Cabe observar, na Figura 11, que a Universidade de São Paulo - USP possui papel central na rede de colaborações, atraindo maior quantidade de instituições à sua volta, seguida pela Universidade Federal de São Carlos - UFSCar.

\section{Conclusões}

As conclusões deste artigo são baseadas na análise de 341 artigos publicados na revista G\&P entre 1999 e 2010. A Revista Gestão \& Produção ocupa uma posição de destaque na comunidade acadêmica brasileira de Engenharia de Produção como um dos mais importantes periódicos na área.

A pesquisa em produção e operações na revista G\&P aumentou em quantidade e qualidade nos últimos anos e difere na essência de journals internacionais como o Production e Operation Management que possuem muito mais foco quantitativo baseado em modelagem e simulações (GUPTA; VERMA; VICTORINO, 2006). A pesquisa qualitativa ainda é fonte importante de informações para os pesquisadores brasileiros, apesar de ser identificado neste trabalho um aumento de pesquisas mais quantitativas em suas publicações. As áreas mais populares de pesquisa são engenharia de operações e processos da produção e engenharia organizacional, justificando o título de periódico de Gestão \& Produção.

Este artigo fornece um ponto de partida para pesquisadores que desejam investigar questões relacionadas à POM e pretende ajudá-los a orientar o foco de investigação de suas agendas por meio da revelação de campos emergentes de pesquisa. $\mathrm{O}$ futuro da pesquisa em POM está repleto de promessas de novos tópicos, como gestão de redes de suprimentos globais, redes de serviços, gerenciamento de receitas, economia digital, uso de novas tecnologias como RFID, operações sustentáveis e o papel dos serviços na economia. Assim, há uma vasta gama de oportunidades para explorar tanto em tópicos tradicionais quanto em novos temas. No debate da agenda de investigação, Wickham Skinner argumenta que "[...] devemos estudar o que fazem os gestores de operações." (SKINNER, 1995 apud HAYES et al., 2004, p. 23). Esse conselho também vale para o campo emergente de pesquisa relacionada à POM no Brasil.

A pesquisa mostrou que as redes sociais estão a cada ano mais conectadas, revelando uma maior troca de informações entre os pesquisadores e o fortalecimento da área de pesquisa. Também se constatou que, além das tradicionais escolas de produção e operações USP e UFSCar, começam a surgir novos centros de pesquisas.

\subsection{Limitações}

Uma das limitações deste trabalho é levar em consideração apenas as publicações da Revista Gestão \& Produção da área de produção e operações. Artigos de outras revistas certamente têm estudos importantes de POM que não foram considerados nesta pesquisa.

A classificação realizada também não consegue refletir a total dimensão dos estudos realizados. $\mathrm{Na}$ tentativa de encaixar os trabalhos investigados dentro do modelo utilizado, algumas simplificações foram realizadas, procurando não perder a integridade e as contribuições de cada estudo.

O número de artigos e de tópicos analisados, juntamente com as limitações de espaço inerentes a um artigo científico, impediu análises profundas dos resultados de cada publicação. Infelizmente, esse é um trade-off inerente ao tipo de trabalho proposto. Futuros estudos poderão focar somente tópicos específicos ou mais amplos, aprofundando as análises aqui iniciadas.

\section{Referências}

ARKADER, R. A pesquisa científica em gerência de operações no Brasil. Revista de Administração de Empresas, v. 43, n. 1, 2003.

BOYER, K. K.; VERMA, R. Multiple raters in survey-based operations management research: a review and tutorial. Production and Operations Management, v. 9, n. 2, p. 128-140, 2000. http://dx.doi. org/10.1111/j.1937-5956.2000.tb00329.x

BUFFA, E. S. Research in operations management. Journal of Operations Management, v. 1, p. 1-8, 1980. http:// dx.doi.org/10.1016/0272-6963(80)90005-4

BUHMAN, C.; KEKRE, S.; SINGHAL, J. Interdisciplinary and Interorganizational Research: Establishing the Science of Enterprise Networks. Productionand Operations Management, v. 14, n. 4, p. 493-513, 2005. http://dx.doi.org/10.1111/j.1937-5956.2005.tb00236.x

CHASE, R. B. A Classification and evaluation of research in operations management. Journal of Operations Management, v. 1, p. 9-14, 1980. http://dx.doi. org/10.1016/0272-6963(80)90006-6

CHARVET, F. F.; COOPER, M. C. The Intellectual Structure of Supply Chain Management: A Bibliometric Approach. Journal of Business Logistics, v. 29, n. 1, 2008. http:// dx.doi.org/10.1002/j.2158-1592.2008.tb00068.x

GODINHO FILHO, M.; FERNANDES, F. C. F. Manufatura Enxuta: uma revisão que classifica e analisa os trabalhos apontando perspectivas de pesquisas futuras. Gestão \& Produção, v. 11, n. 1, 2004. http://dx.doi.org/10.1590/ S0104-530X2004000100002

GOLDMAN SACHS. BRICs and Beyond. London: Goldman Sachs, 2007.

GUPTA, S.; VERMA, R.; VICTORINO, L. Empirical Research Published in Production and Operations Management (1992-2005): Trends and Future Research Directions. Production and Operations 
Management, v. 15, n. 3, p. 432-448, 2006. http:// dx.doi.org/10.1111/j.1937-5956.2006.tb00256.x

HAYES, R. H. et al. Operations, Strategy and Technology, Pursuing the Competitive Edge. New York: John Willey \& Sons, 2004.

INSTITUTO BRASILEIRO DE GEOGRAFIA E ESTATÍSTICA - IBGE. Projeção da população do Brasil por sexo e idade para o período 1980-2050: revisão 2008. Rio de Janeiro: IBGE, 2008. Disponível em: <http://www.ibge.gov.br>. Acesso em: 13 mar. 2012.

MEREDITH, J. R. et al. Alternative research paradigms in operations management. Journal of Operations Management, v. 8, p. 297-326, 1989. http://dx.doi. org/10.1016/0272-6963(89)90033-8

MILLER, J. G.; GRAHAM, M. B.W. Production/ operations management: agenda for the '80s. Decision Sciences, v. 12, p. 547-571, 1981. http://dx.doi. org/10.1111/j.1540-5915.1981.tb00106.x

NEWMAN, M. E. J. From the Cover: the structure of scientific collaboration networks. Proceedings of the National Academy of Sciences of the United States of
America, v. 98, n. 2, p. 404-409, 2001. PMid:11149952. http://dx.doi.org/10.1073/pnas.021544898

SCOTT, J. Social Network Analysis: a handbook. 2. ed. London: Sage Publications, 2000.

SLACK, N.; LEWIS, M.; BATES, H. The Two Worlds of Operations Management Research and Practice Can They Meet, Should They Meet? International Journal of Operations and Production Management, v. 24, n. 4, p. 372-387, 2004. http://dx.doi. org/10.1108/01443570410524640

SPRAGUE, L.G. Evolution of the field of operations management. Journal of Operations Management, v. 25, p. 219-238, 2007. http://dx.doi.org/10.1016/j. jom.2007.01.001

TEIXEIRA, R.; LACERDA, D. P. Supply chain management: analysis of papers published on some journals between 2004 and 2006. Gestão \& Produção, v. 17, n. $1,2010$.

WASSERMAN, S.; FAUST, K. Social Network Analysis: Methods and Applications. Cambridge: Cambridge University Press, 1994. 


\section{Errata/Erratum}

BORTOLLOSSI, L.N.; SAMPAIO, M. A produção acadêmica publicada na revista Gestão \& Produção de 1999 a 2010: tendências e direções para pesquisas futuras. Gestão \& Produção, São Carlos, v. 19, n. 1, p. 189-201, 2012. http://dx.doi. org/10.1590/S0104-530X2012000100013

Na página 198, a Tabela 8 está incorreta.

Onde lê-se:

Tabela 8. Pesquisadores mais prolíferos no período estudado.

\begin{tabular}{lcccc}
\hline \multicolumn{1}{c}{ Autores } & P1 & P2 & P3 & Total \\
\hline Reinaldo Morabito & 5 & 4 & 6 & 15 \\
Marly Monteiro de Carvalho & 2 & 5 & 2 & 9 \\
Miguel Afonso Sellitto & 1 & 5 & 3 & 9 \\
Alceu Gomes Alves Filho & 2 & 3 & 2 & 7 \\
Moacir Godinho Filho & 0 & 3 & 4 & 7 \\
Fernando José Barbin Laurindo & 3 & 3 & 0 & 6 \\
Maria Teresinha Arns Steiner & 1 & 3 & 2 & 6 \\
Aline Lamon Cerra & 1 & 2 & 2 & 5 \\
Daniel Capaldo Amaral & 2 & 0 & 3 & 5 \\
Fernando César Almada Santos & 1 & 2 & 2 & 5 \\
Flávio Sanson Fogliatto & 0 & 3 & 2 & 5 \\
José Luis Duarte Ribeiro & 0 & 3 & 2 & 5 \\
Peter Wanke & 0 & 3 & 2 & 5 \\
Adiel Teixeira de Almeida & 1 & 1 & 2 & 4 \\
Andrea Lago da Silva & 1 & 2 & 1 & 4 \\
Jonas Lúcio Maia & 0 & 2 & 2 & 4 \\
Leandro dos Santos Coelho & 0 & 2 & 2 & 4 \\
Linda Lee Ho & 0 & 3 & 1 & 4 \\
Luiz Antônio Nogueira Lorena & 1 & 1 & 2 & 4 \\
Mário Sérgio Salerno & 1 & 1 & 2 & 4 \\
\hline Font: Osautores. & & & &
\end{tabular}

Fonte: Os autores.
Lê-se:

Tabela 8. Pesquisadores mais prolíferos no período estudado.

\begin{tabular}{|c|c|c|c|c|}
\hline Autores & $\mathbf{P 1}$ & $\mathbf{P 2}$ & $\mathbf{P 3}$ & Total* \\
\hline Reinaldo Morabito & 5 & 4 & 6 & 15 \\
\hline Flávio César F. Fernandes & 3 & 5 & 4 & 12 \\
\hline Miguel Afonso Sellitto & 1 & 5 & 3 & 9 \\
\hline Marly Monteiro de Carvalho & 2 & 5 & 2 & 9 \\
\hline Moacir Godinho Filho & 0 & 3 & 5 & 8 \\
\hline Alceu Gomes Alves Filho & 2 & 3 & 2 & 7 \\
\hline Flávio Sanson Fogliatto & 2 & 3 & 2 & 7 \\
\hline Fernando José Barbin Laurindo & 3 & 3 & 1 & 7 \\
\hline José Luis Duarte Ribeiro & 0 & 3 & 3 & 6 \\
\hline Sílvio R. I. Pires & 1 & 2 & 3 & 6 \\
\hline Maria Teresinha Arns Steiner & 1 & 3 & 2 & 6 \\
\hline Paulo Augusto Cauchick Miguel & 0 & 2 & 3 & 5 \\
\hline Daniel Capaldo Amaral & 2 & 0 & 3 & 5 \\
\hline Peter Wanke & 0 & 3 & 2 & 5 \\
\hline Aline Lamon Cerra & 1 & 2 & 2 & 5 \\
\hline Fernando César Almada Santos & 1 & 2 & 2 & 5 \\
\hline Luiz Fernando de Orini e Paulillo & 1 & 2 & 2 & 5 \\
\hline Jonas Lucio Maia & 0 & 2 & 2 & 4 \\
\hline Leandro dos Santos Coelho & 0 & 2 & 2 & 4 \\
\hline Adiel Teixeira de Almeida & 1 & 1 & 2 & 4 \\
\hline Luiz Antonio Nogueira Lorena & 1 & 1 & 2 & 4 \\
\hline Mario Sergio Salerno & 1 & 1 & 2 & 4 \\
\hline Luiz César Ribeiro Carpinetti & 1 & 1 & 2 & 4 \\
\hline Linda Lee Ho & 0 & 3 & 1 & 4 \\
\hline Andrea Lago da Silva & 1 & 2 & 1 & 4 \\
\hline Miguel Cezar Santoro & 3 & 1 & 0 & 4 \\
\hline
\end{tabular}

* período analisado- Jan/1999 a fev/2010 
Na página 198, a Figura 10 está incorreta.

Onde lê-se:

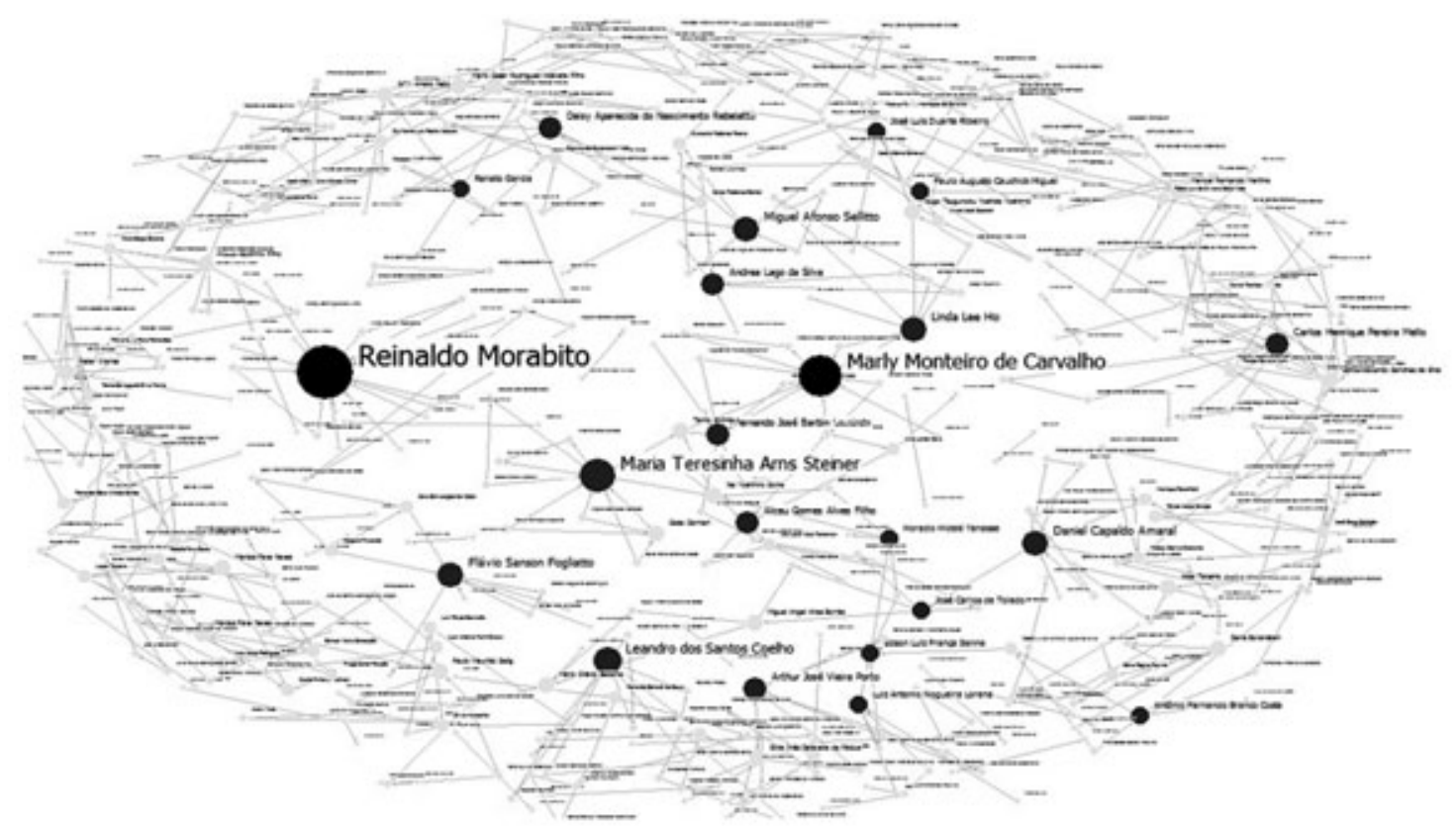

Figura 10. Rede de colaboração entre pesquisadores na Revista Gestão \& Produção. Fonte: Os autores.

Lê-se:

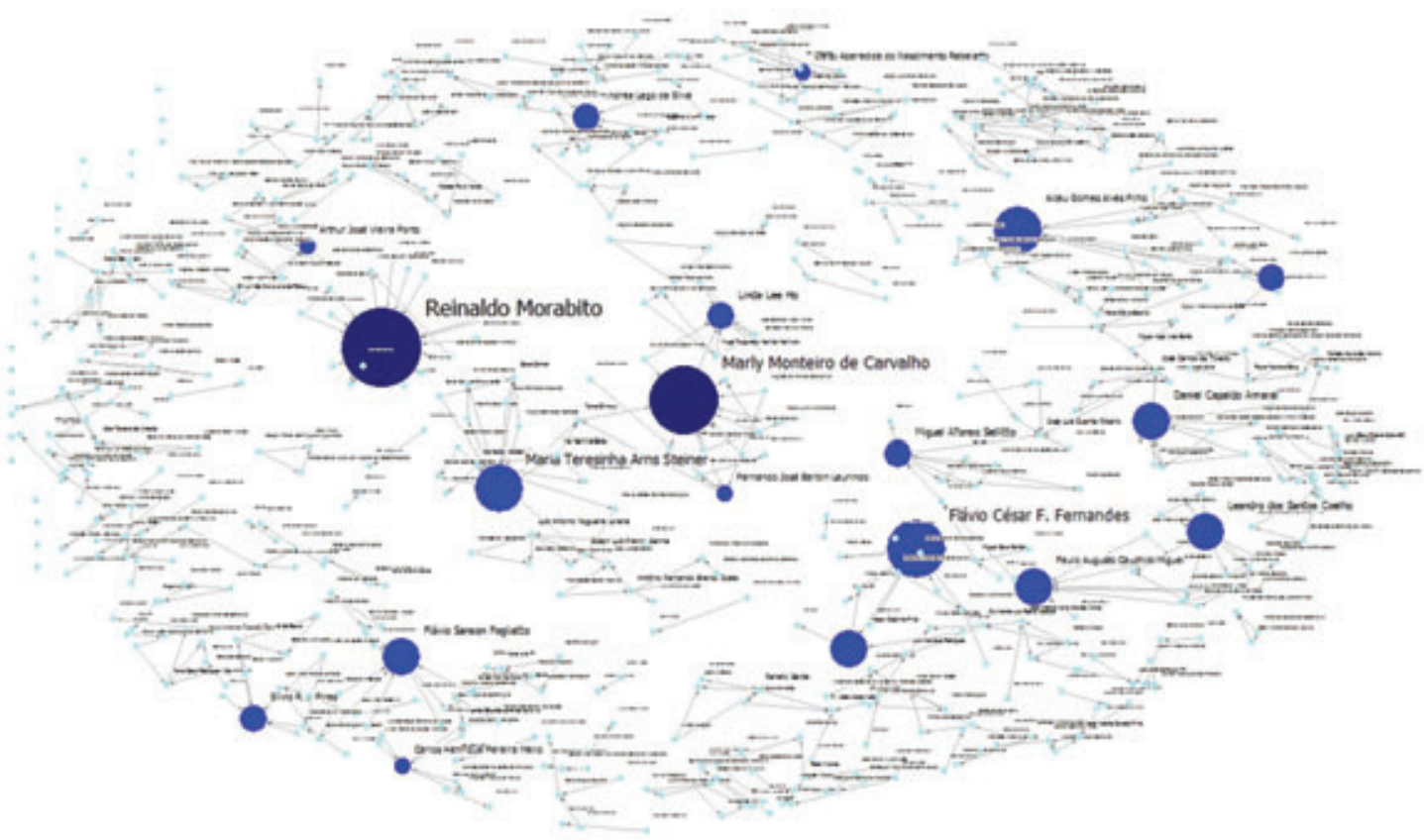

Figura 10. Rede de colaboração entre pesquisadores na Revista Gestão \& Produção. Fonte: Os autores. 
Na página 199, a Tabela 9 está incorreta.

Onde lê-se:

Tabela 9. Grau de centralidade entre pesquisadores.

\begin{tabular}{lc}
\hline \multicolumn{1}{c}{ Autor } & Grau de centralidade \\
\hline Reinaldo Morabito & 16 \\
Marly Monteiro de Carvalho & 14 \\
Maria Teresinha Arns Steiner & 11 \\
Leandro dos Santos Coelho & 8 \\
Miguel Afonso Sellitto & 7 \\
Flávio Sanson Fogliatto & 7 \\
Linda Lee Ho & 7 \\
Daniel Capaldo Amaral & 7 \\
Andrea Lago da Silva & 6 \\
Arthur José Vieira Porto & 6 \\
\hline
\end{tabular}

Fonte: Os autores.
Lê-se:

Tabela 9. Grau de centralidade entre pesquisadores.

\begin{tabular}{clc}
\hline $\mathbf{N}$ & \multicolumn{1}{c}{ Autor } & $\begin{array}{c}\text { Grau de } \\
\text { Centralidade }\end{array}$ \\
\hline 1 & Reinaldo Morabito & 16 \\
2 & Marly Monteiro de Carvalho & 15 \\
3 & Flávio César F. Fernandes & 13 \\
4 & Maria Teresinha Arns Steiner & 11 \\
5 & Alceu Gomes Alves Filho & 10 \\
6 & Daniel Capaldo Amaral & 8 \\
7 & Flávio Sanson Fogliatto & 8 \\
8 & Leandro dos Santos Coelho & 8 \\
9 & Moacir Godinho Filho & 8 \\
10 & Paulo Augusto Cauchick Miguel & 8 \\
\hline
\end{tabular}

